\title{
Monitoring tobacco use and implementation of prevention policies is vital for strengthening tobacco control: an Indian perspective
}

\author{
Prabhdeep Kaur
}

Published online: 19 February 2010

(C) Swiss School of Public Health 2010

Globally tobacco is responsible for 1 in 10 adult deaths. Mortality and morbidity due to tobacco can be prevented by implementation of effective public policies. WHO recently recommended MPOWER package, a combination of six effective tobacco control policies to guide country level tobacco control programs. $\mathrm{M}$ stands for monitoring the tobacco use and prevention policies and $\mathrm{P}$ for protect people from smoke (WHO 2008). Several articles in a recent issue of this journal provide evidence to support these policies.

Tobacco industry targets adolescents as "replacement smokers" for those who die or quit smoking (World Health Organization 2008). Hence, monitoring tobacco use among adolescents is essential to prevent initiation of smoking in the community. The Global Youth Tobacco Surveys (GYTS) that monitor tobacco use among 13-15 years age group reported smoking was prevalent among $22 \%$ boys and 18\% girls in 25 European countries (Baska et al. 2009). Another study from Turkey reported high prevalence of smoking among institutionalized adolescents (Erguder et al. 2009). Majority of the adolescents were exposed to second hand smoke in both the settings (Baska et al. 2009; Erguder et al. 2009). In India, GTYS (2000-2004) results showed current tobacco use was $17.5 \%$ (Reddy and Gupta 2004). The prohibition of sales to minors is an effective regulatory tool which is included in tobacco control programs to prevent tobacco use among youngsters in many countries including India (Government of India 2003). Lazuras et al. (2009) highlighted non-smokers as well as

\section{P. Kaur $(\square)$}

National Institute of Epidemiology (Indian Council of Medical Research), \# R-127, 3rd Avenue, Tamil Nadu Housing Board, Ayapakkam, Chennai 600077, India

e-mail: kprabhdeep@gmail.com current smokers supported the policies against sales of tobacco products to minors in Greece, a country with prosmoking social norms. A major hindrance to implementing this regulation in India is the lack of a mechanism to ensure valid age proof at time of purchase. Recently, India launched an ambitious universal identification number project that will provide unique ID to all citizens and will help overcome this barrier (The economic times 2009). On the other hand, there is also need to enforce penalties for those vendors who fail to adhere to regulations. In India, sale of tobacco within a 100 yards $(90 \mathrm{~m})$ radius of educational institutions is prohibited to restrict tobacco access to the youth (Government of India 2004). In reality, defining "a 90 m radius" remains a hurdle and there is lack of oversight to ensure implementation.

Smoke-free public place is the key intervention adopted in several countries globally to counter prosmoking norms in the communities and to protect people from second hand smoke (Lawrence and Gostin 2007). WHO Framework Convention on Tobacco Control recommended smoke-free environments including all indoor workplaces, indoor public places, and public transport, as well as outdoor public places "as appropriate" (WHO 2007). Government of India implemented "Prohibition of smoking in public places rules, 2008" on 2 October 2008 (Government of India 2008). But there was uncertainty regarding acceptance and compliance with this policy. However, the global workplace smoking survey, conducted in 14 countries (including India) revealed that $71 \%$ of the smoking employees and $87 \%$ of the employers felt that workplace smoking was not acceptable (Halpern and Taylor 2009). This study included smoking employees and therefore might have underestimated the support for smoke-free work places. Lazuras et al. (2009) showed support for restrictions on public places was much higher among 
non-smokers compared to smokers in Greece. These studies indicate that non-smokers and to some extent even smokers will participate in enforcing smoke-free work places. Implementation of smoke-free work places will be good starting point in countries including India to change social norms. But there exists a need for partnership with employers to ensure enforcement of these bans.

The implementation of smoke-free public places outside work settings is more challenging as it is influenced by unique characteristics of smoking culture which may differ in various countries. One of the key characteristics is the socio-demographic profile of smokers. In India, the second largest producer and consumer of tobacco, there is a high prevalence of tobacco use among men (Reddy and Gupta 2004). A large proportion of smokers are from lower socio-economic group with lower level of literacy (Subramanian et al. 2004). A similar pattern was observed in Morocco (Nejjari et al. 2009) Another significant characteristic, though not well studied is "the preferred site for smoking". In India, young adults from lower socio-economic group often smoke in outdoor public places like outdoor open eateries or tea shops where people stand on the road to consume food or drink. Another preferred site is alcohol stores where people purchase and consume alcohol on the street (unpublished data). Future surveys to monitor tobacco use in developing countries need to focus on preferred smoking sites that can provide evidence to tailor smokefree policies at the national level. Indoor smoking bans as implemented in many developed countries may not protect a large proportion of population from second hand smoke in India. Goodman et al. (2009) reviewed health benefits of comprehensive smoke-free laws that can be used for advocacy for smoke-free policies. One of the important outcomes reported in the article is improvement of respiratory health among hospitality workers in indoor settings in developed countries. In India, the equivalent approach may be to assess respiratory health among workers in roadside eateries to build evidence for comprehensive smoking ban.

Though tobacco control policies are in place in many countries, there is need to strengthen the framework for enforcement of policies. We must invest adequate resources for establishing systems for monitoring the level of implementation. While lessons learnt from successful smoke-free policies in developed countries are useful, strategies in developing world needs to be relevant to country, culture and context. Comprehensive smoke-free environments should be the ultimate goal of tobacco control programs.

\section{References}

Baska T, Warren CW, Baskova M, Jones NR (2009) Prevalence of youth cigarette smoking and selected social factors in 25 European countries: findings from the Global Youth Tobacco Survey. Int J Public Health 54:439-445

Erguder T, Cakir B, Babalioglu N, Dogusan H, Turkoral E, Warren CW (2009) Tobacco use among institutionalized adolescents in Turkey: does social environment affect the risk? Int J Public Health 54:379-389

Goodman PG, Haw S, Kabir Z, Clancy L (2009) Are there health benefits associated with comprehensive smoke-free laws. Int $\mathrm{J}$ Public Health 54:367-378

Halpern MT, Taylor H (2009) Beliefs regarding smoking in the work place: results from Global Workplace Smoking Survey. Int J Public Health 54:391-401

Lawrence O, Gostin JD (2007) Global regulatory strategies for tobacco control. JAMA 298(17):2057-2059

Lazuras L, Rodafinos A, Panagiotakos DB, Thyrian JR, John U, Polychronopoulos E (2009) Support for smoke-free policies in a pro-smoking culture: findings from the European survey on tobacco control attitudes and knowledge. Int J Public Health 54:403-408

Ministry of Health, Family Welfare, Government of India (2004) Prohibition on sale of cigarettes and other tobacco products around educational institutions rules. Government of India, New Delhi

Ministry of Health, Family welfare, Government of India (2008) Prohibition of smoking in public places rules, 2008. Government of India, New Delhi

Ministry of Law, Justice, Government of India (2003) The cigarettes and other tobacco products (prohibition of advertisement and regulation of trade and commerce, production, supply and distribution) act 2003. Government of India, New Delhi

Nejjari C, Benjelloun MC, Berraho M, Rhazi KE, Tachfouti N, Elfakir S, Serhier Z, Slama K (2009) Prevalence and demographic factors of smoking in Morocco. Int $\mathrm{J}$ Public Health 54:447-451

Reddy KS, Gupta PC (eds) (2004) Report on tobacco control in India. Ministry of Health and Family Welfare, Government of India, New Delhi

Subramanian SV, Nandy S, Kelly M, Gordon D, Smith GD (2004) Patterns, distribution of tobacco consumption in India. Cross sectional multilevel evidence from the 1998-1999 national family health survey. BMJ 328:801-806

The Economic times (2009) Universal ID: going beyond smart cards and databases. Available at http://economictimes.indiatimes. com/infotech/software/Universal-ID-Going-beyond-smart-cardsdatabases/articleshow/4856509.cms

World Health Organisation (2008) Report on the global tobacco epidemic, 2008. The MPOWER package. WHO, Geneva

World Health Organization (2007) Protection from exposure to second-hand tobacco smoke: policy recommendations. WHO, Geneva 